\title{
Effect of rear suspension and speed on seat forces and head accelerations experienced by manual wheelchair riders with spinal cord injury
}

\author{
Philip S. Requejo, PhD; ${ }^{1 *}$ Grigor Kerdanyan, MS; ${ }^{1}$ Jean Minkel, PT; ${ }^{2}$ Rodney Adkins, PhD; ${ }^{1}$ Robert Waters, MD $^{1}$ \\ ${ }^{1}$ Rehabilitation Engineering Program, Rancho Los Amigos National Rehabilitation Center, Downey, CA; ${ }^{2}$ Minkel \\ Consulting, New Windsor, NY
}

\begin{abstract}
Whole-body shocks and vibrations experienced during manual wheelchair use can decrease an individual's comfort, increase the rate of fatigue, result in injury, and consequently limit mobility and community participation. We used a wheelchairvibration simulator to examine whether the seat reaction forces experienced by wheelchair users were differentially influenced by wheelchair suspension, trunk-muscle innervations, and ground speed. We used wheelchairs instrumented with load cells and accelerometers to determine the forces transmitted from the seat frame and the head accelerations experienced by riders. We determined that self-selected speed, seat force, and head accelerations differed between subjects with and without trunk-muscle innervations and between rigid and suspension wheelchairs. Seat force and head accelerations were greatest in the rigid-frame wheelchair and lowest in the spring-type suspension-frame wheelchairs. Those participants without trunk-muscle innervations preferred slower speeds than those with trunk-muscle innervations. Forward head accelerations were greater in those without than with trunk-muscle innervations. Wheelchair rear-suspension systems may improve wheelchair mobility function in terms of comfort at higher velocity by minimizing the seat forces and head accelerations experienced by the riders, especially those with higher level spinal cord injury and diminished postural control.
\end{abstract}

Key words: acceleration, force, human vibration, mobility, rehabilitation, spinal cord injury, suspension system, trunk control, wheelchair, whole-body vibrations.

\section{INTRODUCTION}

For many persons with a spinal cord injury (SCI), a common method of mobility is a wheelchair. Over the past
30 years, many improvements in the design and function of wheelchairs and seating systems have made them better fitting and more functional. While individuals with SCI are leading longer and active lives, wheelchair comfort has been a growing concern. In particular, exposure to wholebody vibrations exceeding standards set for industrial occupations [1-2] has been documented during wheelchair use [3-6]. Exposure to high loads and repeated low loads has been linked to muscle fatigue [7], back injury [8-9], and neck pain [10]. Consequently, shocks and vibrations experienced during manual wheelchair propulsion can decrease an individual's comfort [11], increase his or her rate of fatigue [3], and limit his or her activity and participation [12]. Only recently has systematic research investigated wheelchair mobility with regard to exposure to shocks (single-impact events) and vibrations (low-magnitude repeated bumps) $[3-6,13]$. When vibrations were low, discomfort was

\footnotetext{
Abbreviations: Ah1 = first peak horizontal head acceleration, Ah2 $=$ second peak horizontal head acceleration, Av1 = first peak vertical head acceleration, Av2 = second peak vertical head acceleration, F1 = first peak vertical seat reaction force, F2 = second peak vertical seat reaction force, ISO = International Organization for Standardization, SCI $=$ spinal cord injury, SS = self-selected speed.

*Address all correspondence to Philip S. Requejo, PhD; Rehabilitation Engineering Program, Rancho Los Amigos National Rehabilitation Center, 7601 E. Imperial Highway, Building 500, Room 64, Downey, CA 90242; 562-401-7994; fax: 562-803-6117. Email: prequejo@larei.org DOI: 10.1682/JRRD.2008.01.0006
} 
dominated by the static factors (e.g., cushion stiffness); as shocks and vibrations increased, the dynamic component (e.g., bumpy road) dominated the feeling of discomfort [14]. Beyond these findings, little is known regarding the effects of wheelchair shocks and vibrations on body tissues (skin, muscle, and internal organs) or body functions (spasticity, muscle tone, and autonomic function) or how to minimize these adverse effects.

The cumulative amount of shocks and vibrations experienced by the wheelchair and riders is typically evaluated through measurement of forces and accelerations at strategic locations. The accelerations at the hub (SmartHub $^{\circledR}$ ) and caster (SmartCaster ${ }^{\circledR}$ ) have been used to evaluate the effect of the reaction forces applied to both wheelchair and rider [15]. To evaluate the corresponding response to such forces, some researchers have used skinmounted accelerometers to measure accelerations of the legs [16] and spine [17-18], while others have used an accelerometer-mounted bite bar to determine head vertical acceleration [3,18-19]. Time- and frequency-domain analyses have been performed to understand the relationship between the vibration exposures and effects on human health, comfort, and performance. Techniques for assessing vibration include seat-to-head transmissibility analysis $[4,20]$, apparent mass analysis [17,21], root-mean-square analysis [6], absorbed power analysis [22-23], modal analysis [18], transfer function analysis [3], and mechanical impedance analysis [24-25]. Assessment of seating comfort level is generally predicted with psychophysical techniques that combine subjective measures [26] with stiffness and vibration characteristics [14]. While these analysis techniques provide valuable information regarding the level of exposure, the actual forces acting on the rider at the seat interface and the corresponding accelerations of the body through the head can provide objective information regarding the wheelchair rider's response and reaction to repeated seat forces.

Individuals with SCI perform almost all daily functional activities in a seated position. This position increases static and dynamic loads on the intervertebral discs and stresses the posterior structures of the back and spine. For individuals with tetraplegia and high paraplegia, paralysis of critical trunk-stabilizing musculature greatly impairs sitting balance [27]. By "slouching" in a "C"-shaped posture, patients lacking normal extensor function of the trunk and hips achieve some passive stability by shifting their trunk center of mass more posteriorly, thereby decreasing the need for trunk extension.
However, this adaptive posture leads to increased thoracic kyphosis, a more forward head position, cervical hyperextension, and protracted scapulae [28]. With exposure to shocks and vibrations, this posture can lead to a negative biomechanical chain of events that contributes to increased development of neck and back discomfort and pain [10]. A more complete understanding of shock and vibration exposure from wheelchair riding in individuals with varying levels of SCI may improve comfort and ride quality through optimal seating interventions and equipment design and may help delay the onset of the welldocumented accelerated functional changes found among persons who are aging with a disability [29].

To improve ride quality, manufacturers have developed innovative frame, seating, and suspension system designs to reduce the effects of shocks and vibration. Different types and components of suspension systems are commercially available. These units include an independent suspension system using coil springs attached to the wheelchair frame (Boing! ${ }^{\circledR}$, Colours 'N Motion Inc; Corona, California), a single spring-damper suspension unit supporting the wheelchair seat (Quickie XTR ${ }^{\circledR}$, Sunrise Medical; Carlsbad, California), and polymer-based units supporting each wheel ( $\mathrm{A} 4{ }^{\circledR}$, Invacare Corp; Elyria, Ohio). While these units are all designed to minimize a harsh ride by reducing the external reaction forces transmitted to the rider when he or she is going over bumps and descending curbs, the magnitude and direction of these forces and the dynamic response of actual wheelchair riders are yet to be evaluated. Quantifying the response of wheelchair riders with varying levels of trunk and muscular control to different suspension mechanisms will provide evidence-based justification for the prescription of suspension-frame wheelchairs. A greater understanding of the specific factors contributing to fatigue, the onset of secondary injury, and the prevention of such injuries through an evidence-based approach will lead to development of interventions that aim to enhance mobility and community participation.

This study determined the forces transmitted from the seat and the accelerations experienced by wheelchair riders of varying trunk innervations who were exposed to repeated bumps while seated on wheelchairs with either rigid- or rear-suspension-type frames. We hypothesized that wheelchair riders with and without trunk-muscle innervations would respond differently to the applied forces and experience accelerations as a function of wheelchair frame type and speed of the bumps. For individuals with tetraplegia and high paraplegia, paralysis of critical trunk-stabilizing 
musculature greatly impairs sitting balance. Consequently, individuals with no trunk innervations will have greater head-acceleration responses to the applied seat forces and consequently prefer a slower speed than individuals with trunk innervations and greater trunk control. Our ultimate aim is to develop an objective assessment of the human body's response to shocks and vibration and to establish the relationship of this response to wheelchair seating comfort and ride quality in wheelchair users with SCI.

\section{METHODS}

\section{Participants}

Ten males who had complete SCI (American Spinal Injury Association A or B) and were full-time manual wheelchair users were asked to volunteer. The volunteers were classified into two functional categories: High SCI $(n=5)$ and Low SCI $(n=5)$. The High SCI group (weight range: 138-176 lb [63-80 kg]) were those with an SCI lesion at or above the fourth thoracic level. The Low SCI group (weight range: 161-250 lb [73-113 kg]) were those with an SCI lesion at or below the twelfth thoracic level. The primary difference between these two functional categories is the level of trunk control. Those with High SCI have no trunk control, while those with Low SCI have nearly intact trunk strength with innervated abdominals and thoracic extensors but not lumbar extensors. The volunteers were recruited from the outpatient services at Rancho Los Amigos National Rehabilitation Center in Downey, California. Before data collection, we asked the volunteers to read and sign an informed consent form that had been approved by the Rancho Los Amigos Institutional Review Board. We performed all testing at the Rehabilitation Engineering Department located at Rancho Los Amigos National Rehabilitation Center.

\section{Instrumentation}

We instrumented one rigid-frame wheelchair (Quickie GPV, Sunrise Medical) and three suspension-frame wheelchairs (Boing!, A4, and Quickie XTR) with load cells (MLP Series, Transducer Techniques; Temecula, California), as previously described by Kerdanyan et al. [16] (Figure 1). The load cell's maximum force range is $500 \mathrm{lb}$ for vertically oriented and $300 \mathrm{lb}$ for horizontally oriented load cells. We fabricated a lightweight aluminum seat frame to allow instrumentation. We strategically placed seven load cells below the seat and backrest frame to record the vertical (z), fore-and-aft $(x)$, and lateral $(y)$ seat reaction forces acting on the rider (Figure 2). The seat frame and backrest were entirely supported by the load cells through a ball-joint eyebolt. Four load cells were oriented vertically to measure the seat vertical and horizontal reaction forces

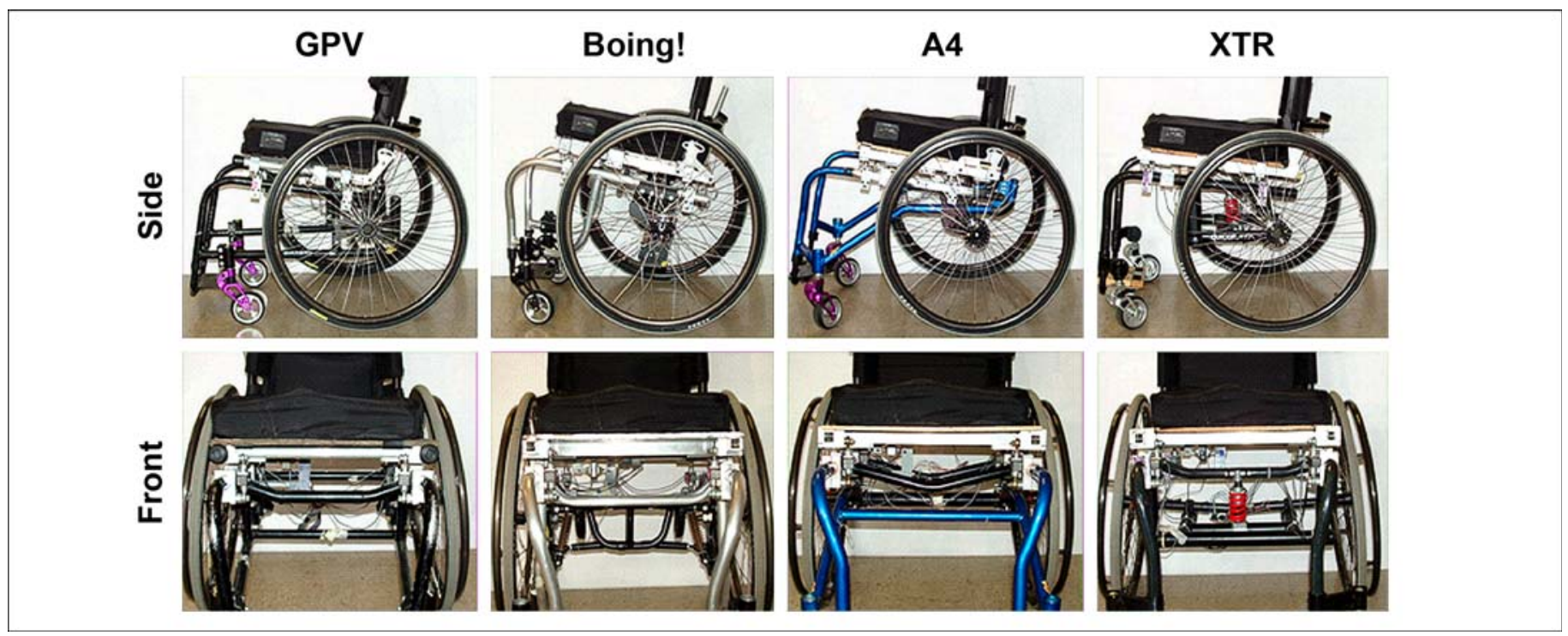

Figure 1.

One rigid-type frame wheelchair (Quickie GPV [Sunrise Medical; Carlsbad, California]) and three suspension-type frame wheelchairs (Boing! [Colours 'N Motion Inc; Corona, California], A4 [Invacare Corp; Elyria, Ohio], and Quickie XTR [Sunrise Medical]) were instrumented to measure seat reaction forces and accelerations. 


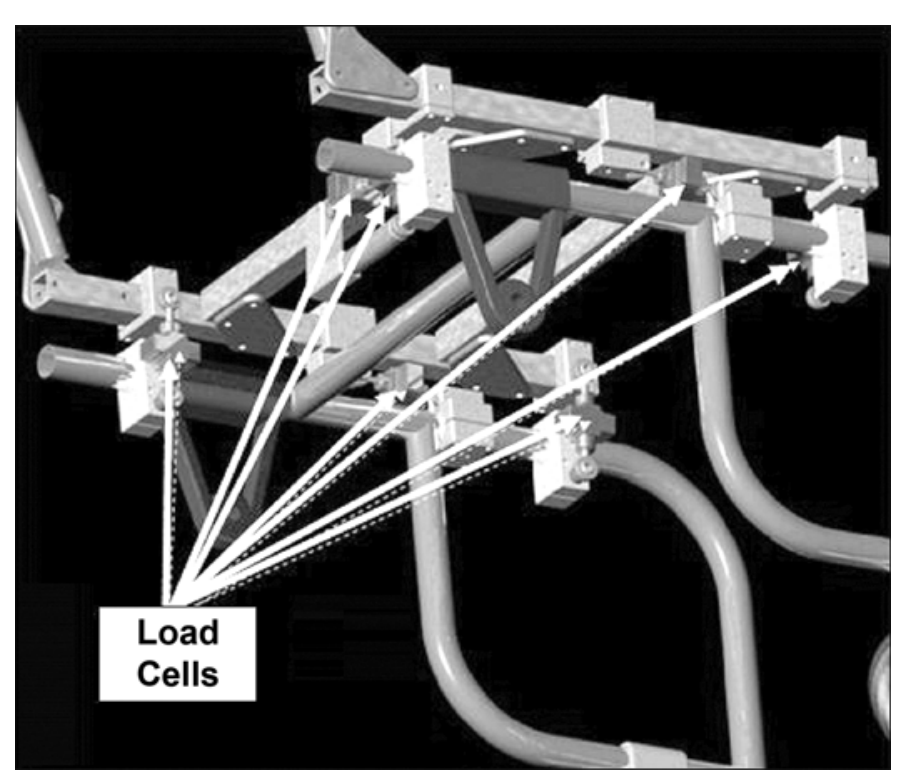

Figure 2.

Seven load cells placed below seat and backrest frame for recording vertical (z), fore-and-aft $(x)$, and lateral $(y)$ seat reaction forces.

as well as to constrain the vertical translation, pitch, and roll of the seat. We mounted two load cells horizontally over the wheels to measure horizontal (fore-and-aft) forces as well as to constrain the backward and forward translation and yaw of the seat. Finally, we placed a load cell to measure the lateral force and constrain the side-to-side translation. All load cells were placed perpendicular to one other to prevent signal cross-contamination. To establish the accuracy of the instrumented seat frame, we applied known loads to the frame in different directions at different locations. From the measured signals, we determined the force magnitudes, the direction, and point of force application. The weights (excluding the cushion) of each instrumented wheelchair were GPV = $15.6 \mathrm{~kg}$, Boing! $=19.3 \mathrm{~kg}, \mathrm{XTR}=18.4 \mathrm{~kg}$, and $\mathrm{A} 4=16.8 \mathrm{~kg}$.

We used accelerometers to measure the loads entering the chair through the wheel hub, reaching the seat, and finally reaching the rider. For each wheelchair, we mounted four 1-axis capacitive micromachined accelerometer modules (Model 2210, Silicon Designs; Issaquah, Washington) on the following areas: two on a bicycle helmet worn by the test subject to measure vertical and horizontal accelerations, one on the posterior right corner of the instrumented seat frame, and one on the right hub of the wheel. The accelerometer modules were chosen because of their rugged construction, low power consumption, full calibration, and simple four-wire connection. The high-drive, lowimpedance output allowed longer cable connection with minimal noise, suitable for evaluating under more dynamic conditions (e.g., traversing a course, curb descents). The head accelerometer measurement ranges were $\pm 10 \mathrm{~g}$ for the vertical and $\pm 5 g$ for horizontal accelerations. These ranges were chosen based on pilot evaluation that used a platform to identify the peak head accelerations experienced during independent curb descents and vertical drops. The portable data acquisition system we used to collect the data consisted of a personal computer laptop, two PCMCIA cards (DAQP-12H and DAQP-16, Quatech Inc; Hudson, Ohio), a battery pack, and a voltage regulator. The DAQP-12H contains eight differential channels with up to $1,000 \times$ gain and was used to collect load cell data. The DAQP-16 contains eight differential channels with $8 \times$ gain and was used to collect accelerometer data. Force and acceleration data were collected at 2,000 $\mathrm{Hz}$ and saved into the hard drive for processing and analyses.

We developed a vibration simulator to apply small but frequent bumps to the rider (Figure 3(a)). A ball-and-socket joint restrained the front of the instrumented chair while the rear wheels were placed over a rotating drum with a small metal rod fixed along the drum length. Drum rotation was provided by a direct current motor (General Electric; Fairfield, Connecticut) controlled by an electronic speed controller (Leeson Electric Corporation; Grafton, Wisconsin). The roller speed, size, shape, and orientation of the rod were changeable. In this study, we used a 3/8-inch-diameter metal rod impacting both wheels simultaneously (Figure 3(b)). We also built a transfer platform to elevate the subjects in their own chair to the level of the instrumented chair, in and out of which they transferred.

\section{Data Collection}

We recorded seat reaction forces and head acceleration from subjects in each instrumented wheelchair with the subject sitting on his or her own cushion and the height of the footrest and backrest adjusted to match his or her personal wheelchair (Figure 4). The subject's sitting posture was further confirmed by the research physical therapist, who has extensive experience in wheelchair seating and positioning. All wheelchairs were mounted with the same make and model tires (Model 23-540, Kenda; Reynoldsburg, Ohio) inflated to 80 psi. Before data collection in each chair, we collected a 5-second baseline trial (while subject was off the chair) and a seated weight trial (while subject sat motionless and looking forward in the chair). 


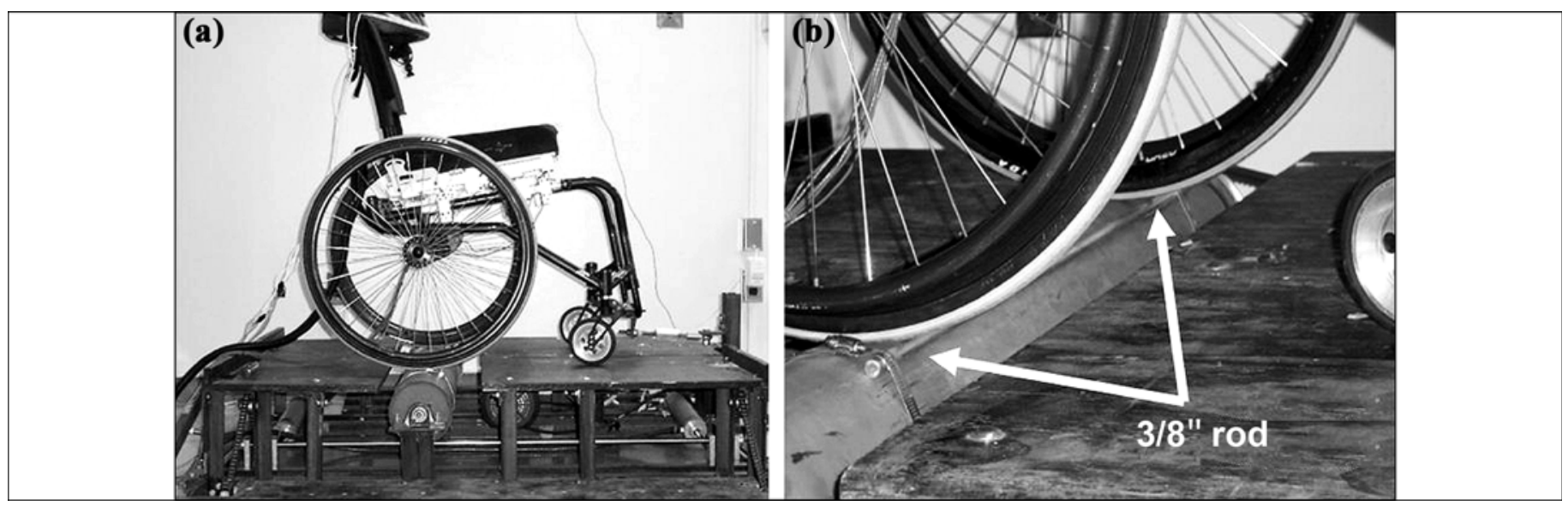

Figure 3.

(a) Vibration simulator used to apply small but repeated bumps to wheelchair and rider though rear wheels. (b) 3/8 in.-diameter metal rod was attached to motor-controlled rotating drum.
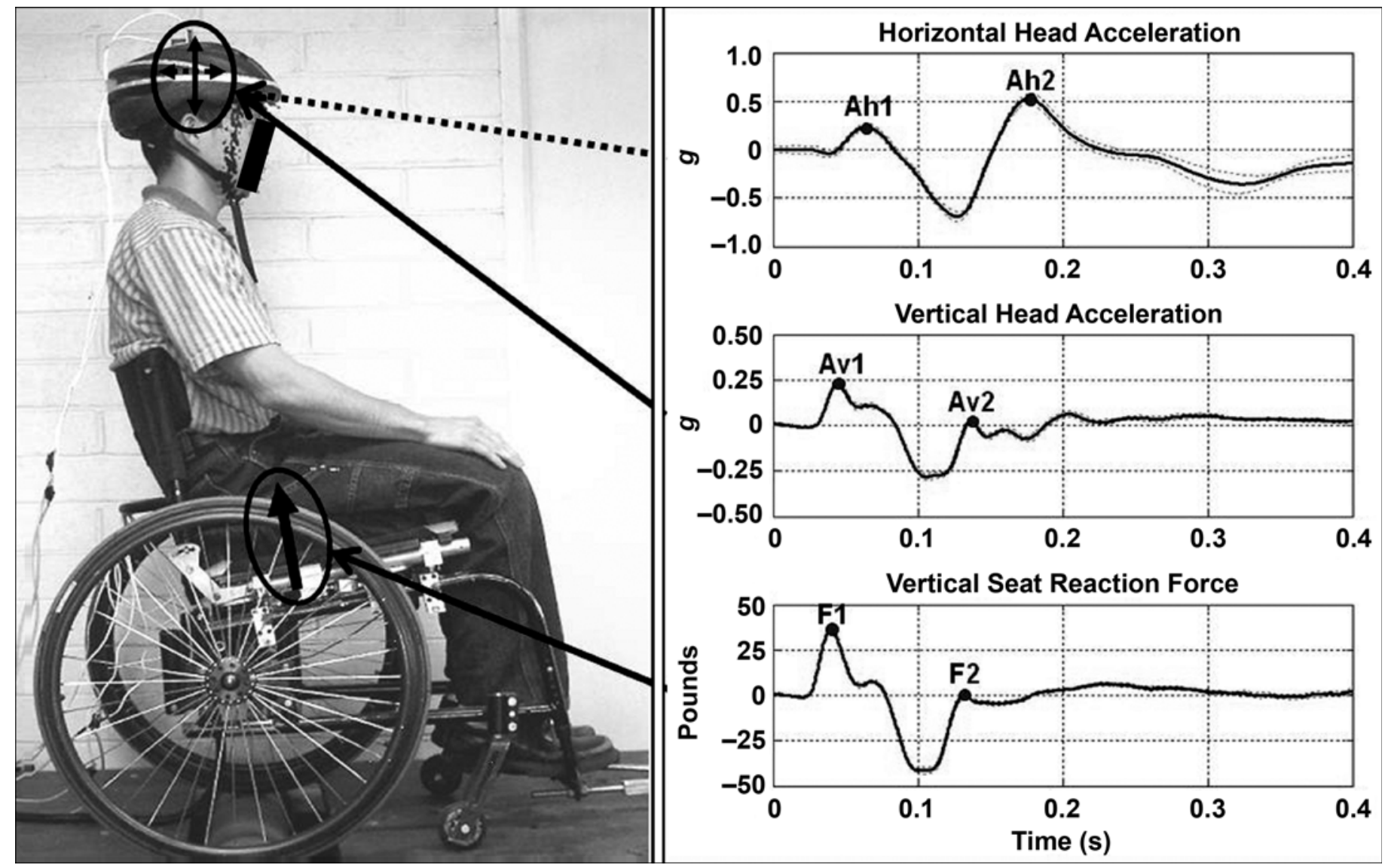

Figure 4.

Peak analysis procedure applied to force and accelerations experienced by wheelchair rider during each bump. First peak vertical seat reaction force (F1) and vertical (Av1) and horizontal head accelerations (Ah1) occurred when metal rod impacted rear tires. Second peak vertical seat reaction force (F2) and vertical (Av2) and horizontal head accelerations (Ah2) occurred when rear tires landed on rotating drum. Consecutive bumps were averaged to produce mean \pm standard deviation bump profile. 
Then, we collected data for 30 seconds at three predetermined ground speeds $(0.85,1.03$, and $1.21 \mathrm{~m} / \mathrm{s})$ and a selfselected speed (SS). During the SS trial, the drum rotation speed was adjusted until the subject signaled that a maximum overall level of comfortable speed setting had been reached; then we collected the data. For all trials, we instructed the subjects to maintain a constant posture and look straight forward.

\section{Data Processing and Analysis}

We applied a zero-phase fourth-order digital Butterworth low-pass filter (MATLAB, The MathWorks, Inc; Natick, Massachusetts) with cutoff frequency of $114 \mathrm{~Hz}$ to the load cell and accelerometer data and scaled them to determine seat reaction forces (in Newtons) and head vertical and horizontal accelerations (in $g$ [acceleration of gravity]). We referenced the forces to the three axes $(x, y, z)$ relative to the chair coordinate system (Figure 2). To set the baseline seat force to zero, we subtracted the vertical seat force of the seated weight trial from the vertical seat force of the test trial. Likewise, to set the baseline head acceleration to zero, we subtracted the vertical head accelerations of the seated static trial from the test trial.

Since the collected force and acceleration data were repeatable and consistent during the 30-second time interval, we used a time-domain analysis of the vertical seat force and vertical and horizontal head accelerations by identifying the peak forces (relative to seated weight) and head accelerations (relative to static $\left[\begin{array}{ll}0 & g\end{array}\right]$ ) that were recorded when the metal rod impacted the rear wheels (Figure 4). We further limited the analysis to the first and second positive peak of the seat reaction force and head vertical and horizontal accelerations. The first peak vertical seat reaction force (F1), vertical head acceleration (Av1), and horizontal head acceleration (Ah1) occurred when the metal rod impacted the rear tires. During this interval, the rider experienced an upward seat reaction force, resulting in upward and forward head accelerations. The second peak vertical seat reaction force (F2), vertical head acceleration (Av2), and horizontal head acceleration (Ah2) occurred when the rear tires landed on the rotating drum, resulting in an upward seat reaction force and upward and forward head acceleration. Negative peak oscillations of the seat force and head accelerations were also considered but were excluded from further analysis. A total of 15 to 20 consecutive bumps for each speed con- dition per chair was averaged. Data were analyzed with SPSS 12.0 software (SPSS, Inc; Chicago, Illinois).

\section{RESULTS}

The Shapiro-Wilk statistic determined that seat force, accelerations, and speeds were normally distributed. Therefore, parametric statistics were used. To determine whether the seat forces and vertical and horizontal head accelerations were differentially influenced by wheelchair suspension, level of SCI, and velocity, we applied a mixed-model analysis of covariance with one between-subjects factor (High vs Low SCI) and two within-subjects factors (chair type and velocity), controlling for subject mass. We set the significance level to 0.05 . Data are presented as mean \pm standard deviation unless otherwise indicated.

\section{Self-Selected Speed}

The SS was slower for the High than the Low SCI group ( $p=0.011$ ) for all wheelchairs; the speed was lowest in the rigid frame (GPV) compared with the suspension frames (Boing!, A4, XTR) (Figure 5). For the Low SCI group, the SS was fastest in Boing! $(1.11 \pm 0.22 \mathrm{~m} / \mathrm{s})$, followed by A4 $(0.98 \pm 0.089 \mathrm{~m} / \mathrm{s})$, XTR $(0.98 \pm 0.089 \mathrm{~m} / \mathrm{s})$, and GPV $(0.89 \pm 0.13 \mathrm{~m} / \mathrm{s})$. For the High SCI group, the SS was greatest in the XTR $(0.94 \pm 0.27 \mathrm{~m} / \mathrm{s})$ and Boing! $(0.89 \pm 0.22 \mathrm{~m} / \mathrm{s})$, followed by A4 $(0.85 \pm 0.31 \mathrm{~m} / \mathrm{s})$ and GPV $(0.72 \pm 0.90 \mathrm{~m} / \mathrm{s})$.

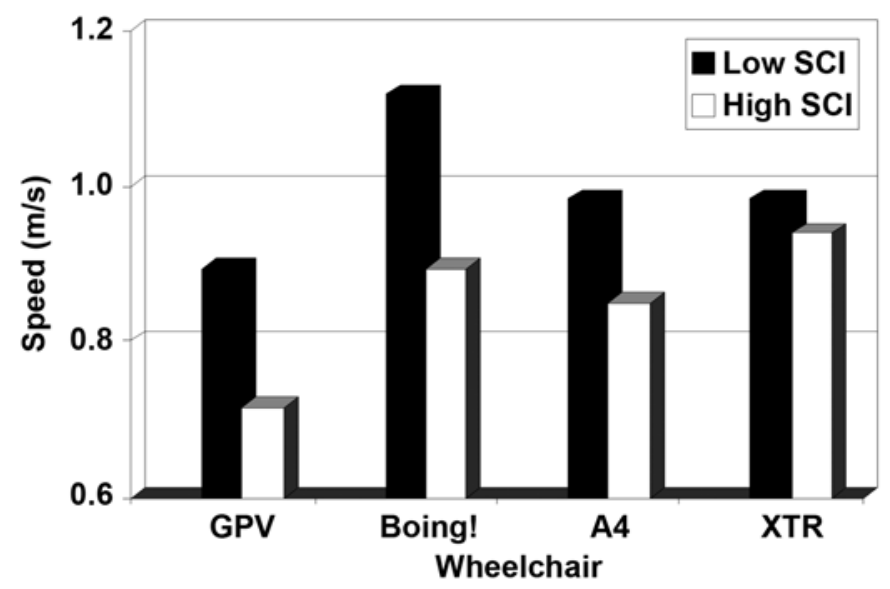

Figure 5.

Self-selected speed in meters/second between subjects with high- and low-level spinal cord injury (SCI) in Quickie GPV (Sunrise Medical; Carlsbad, California), Boing! (Colours 'N Motion Inc; Corona, California), A4 (Invacare Corp; Elyria, Ohio), and Quickie XTR (Sunrise Medical) wheelchairs. 


\section{Vertical Seat Reaction Force}

First Peak Seat Reaction Force

When seated weight of the participants was controlled for, the F1 was different for the different chairs regardless of speed ( $p<0.001$; Figure 6(a)) and different speeds produced different peak seat force for all chairs $(p=0.006$; Figure 6(b)-(d)). In the SS condition, the F1 of GPV (High $\mathrm{SCI}=29 \pm 2 \mathrm{~N}$; Low SCI $=36 \pm 5 \mathrm{~N})$ was highest, followed by A4 (High SCI = $25 \pm 7 \mathrm{~N}$; Low SCI $=32 \pm 10 \mathrm{~N}$ ), XTR (High SCI $=21 \pm 5 \mathrm{~N}$; Low SCI $=22 \pm 2 \mathrm{~N}$ ) and Boing! (High SCI = $16 \pm 2$ N; Low SCI = $20 \pm 3$ N) (Figure 6(a)). Increasing speeds resulted in increased F1 in all chairs but the Boing! (Figure 6(b-d)). Moreover, Boing! had the lowest $\mathrm{F} 1$ of all chairs in all conditions.

\section{Second Peak Seat Reaction Force}

The F2 was different for the Low SCI and High SCI groups ( $p=0.02)$, different for the different chairs ( $p=$ 0.001 ) regardless of speed, and different at different speeds for all chairs $(p=0.005)$. The F2 did not increase with increasing speed. In the SS condition, the F2 of GPV (High SCI $=9.5 \pm 3.0 \mathrm{~N}$; Low SCI $=12.4 \pm 3.5 \mathrm{~N}$ ) and XTR (High SCI $=10.7 \pm 3.5 \mathrm{~N}$; Low SCI $=10.9 \pm 3.1 \mathrm{~N}$ ) were highest, followed by A4 (High SCI $=4.7 \pm 2.5 \mathrm{~N}$; Low
SCI $=9.4 \pm 2.4 \mathrm{~N}$ ) and then Boing! (High SCI $=4.3 \pm 1.0 \mathrm{~N}$; Low SCI $=8.2 \pm 2.8 \mathrm{~N}$ ) (Figure 6(a)). Likewise, Boing! had the lowest F2 of all chairs in all conditions (Figure 6(b)-(d)).

\section{Head Accelerations}

\section{First Peak Vertical Head Acceleration}

The Av1 was different for the different chairs $(p<$ 0.001 ) regardless of speed (Figure $7(\mathbf{a})$ ). In the SS condition, the Av1 of GPV (High SCI $=0.21 \pm 0.06 \mathrm{~g}$; Low SCI = $0.25 \pm 0.10 \mathrm{~g}$ ) was highest, followed by A4 (High SCI = $0.17 \pm 0.10 \mathrm{~g}$; Low SCI $=0.22 \pm 0.10 \mathrm{~g}$ ), XTR (High SCI $=$ $0.16 \pm 0.06 \mathrm{~g}$; Low SCI $=0.17 \pm 0.04 \mathrm{~g}$ ), and Boing! (High SCI $=0.11 \pm 0.03 g$; Low SCI $=0.15 \pm 0.06 g)$. Boing! had the lowest Av1 in all speed conditions (Figure 7(b)-(d)). The Av1 tended to increase with increasing speed for all chairs and tended to be lower in the High SCI than the Low SCI group but was not statistically significant.

\section{Second Peak Vertical Head Acceleration}

The Av2 tended to be lower in the High SCI than the Low SCI group and increased with increasing speed but was not statistically significant (Figure 7(b)-(d)). (a)

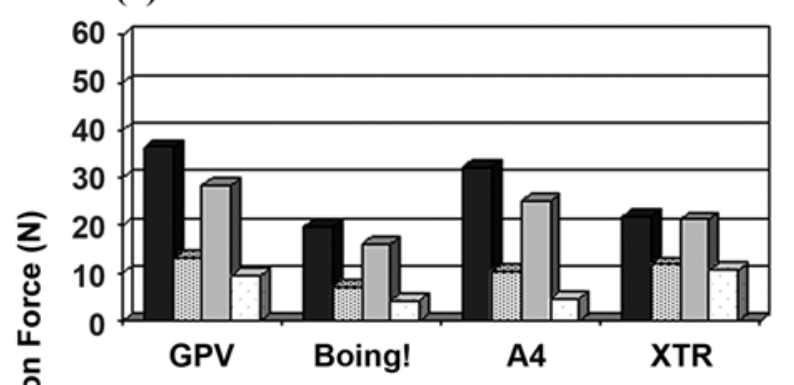

(c)

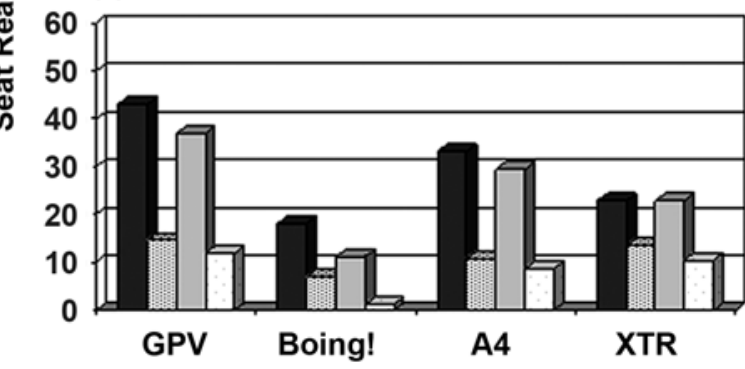

(b)

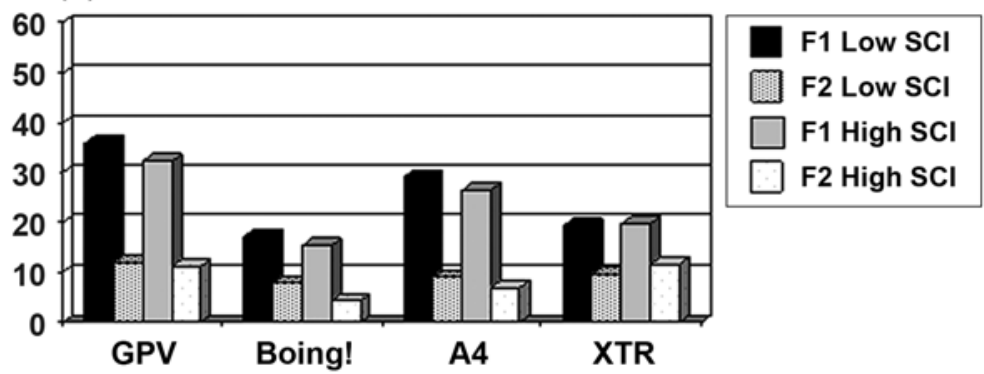

(d)

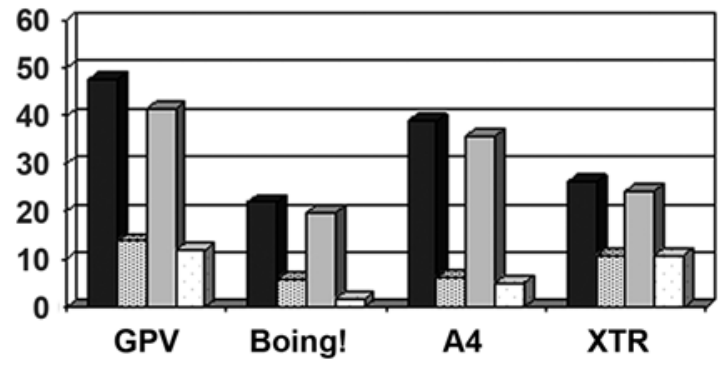

Wheelchair

Figure 6.

First (F1) and second peak vertical seat reaction force (F2) between subjects with high- and low-level spinal cord injury (SCI) in all wheelchairs during trials at (a) self-selected speed, (b) $0.85 \mathrm{~m} / \mathrm{s}$, (c) $1.03 \mathrm{~m} / \mathrm{s}$, and (d) $1.21 \mathrm{~m} / \mathrm{s}$. 
(a)

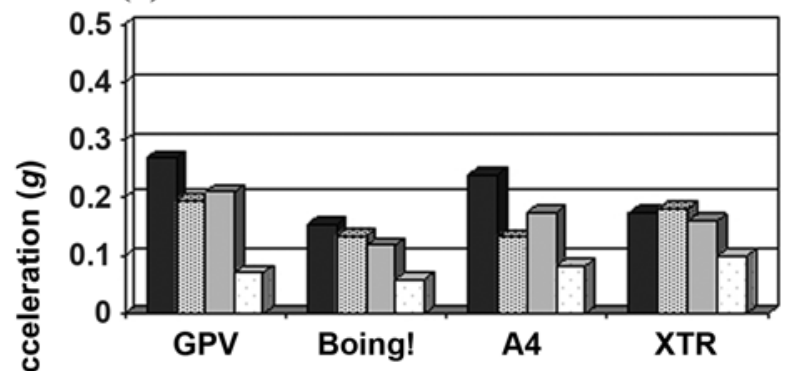

(c)

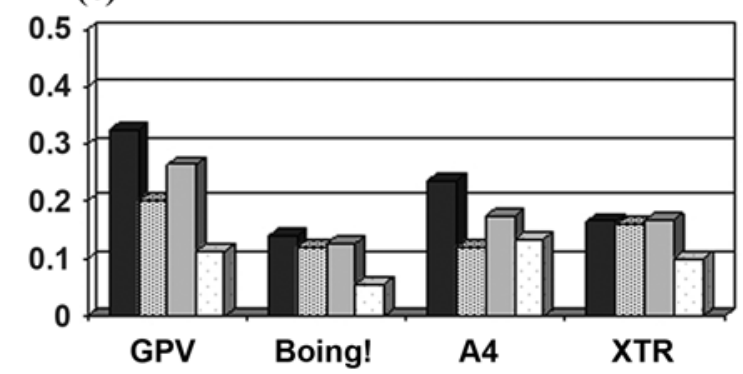

(b)

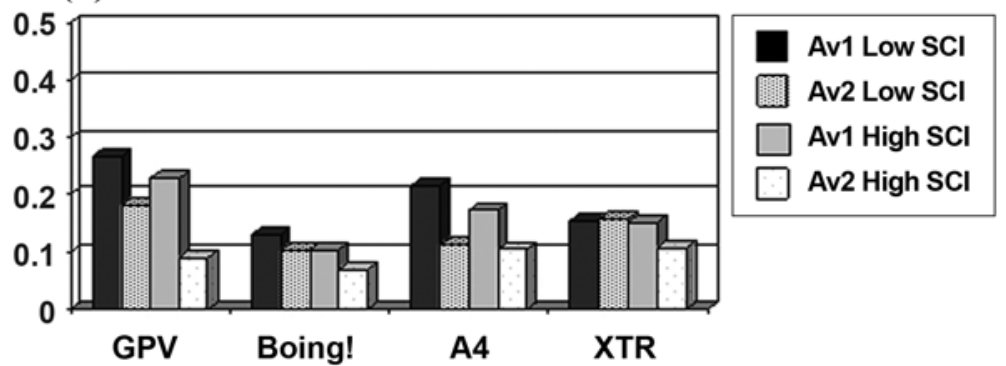

(d)

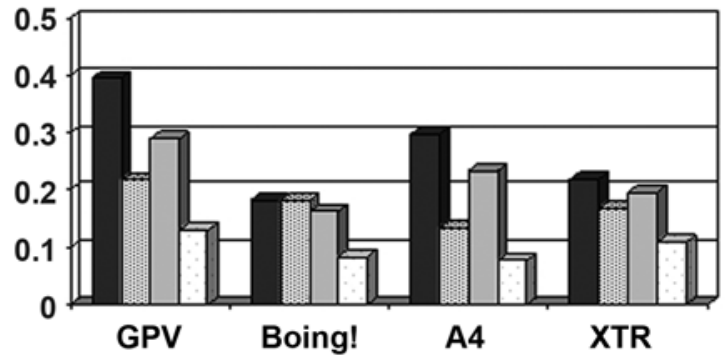

Wheelchair

Figure 7.

First (Av1) and second peak vertical head accelerations (Av2) between subjects with high- and low-level spinal cord injury (SCI) in all wheelchairs during trials at (a) self-selected speed, (b) 0.85 m/s, (c) 1.03 m/s, and (d) 1.21 m/s.

First Peak Horizontal Head Acceleration

The Ah1 was different for the different chairs $(p=$ 0.017) regardless of speed (Figure 8(a)). In the SS condition, GPV (High SCI $=0.27 \pm 0.10 \mathrm{~g}$; Low SCI $=0.25 \pm$ $0.11 \mathrm{~g}$ ) and A4 (High SCI $=0.22 \pm 0.08 \mathrm{~g}$; Low SCI $=$ $0.14 \pm 0.12 \mathrm{~g}$ ) had the highest Ah1, while Boing! (High $\mathrm{SCI}=0.14 \pm 0.05 \mathrm{~g}$; Low SCI $=0.11 \pm 0.08 \mathrm{~g}$ ) and XTR (High SCI $=0.22 \pm 0.06 \mathrm{~g}$; Low SCI $=0.12 \pm 0.08 \mathrm{~g}$ ) had the lowest (Figure 8(b)-(d)). The High SCI group tended to have greater Ah1 than the Low SCI group for all suspension type chairs (A4, XTR, Boing!) but was not statistically significant.

\section{Second Peak Horizontal Head Acceleration}

The Ah2 was different for the Low SCI and High SCI groups ( $p=0.048)$ and different for the different chairs $(p=$ 0.05 ) regardless of speed; the Ah2 was different for the High SCI and Low SCI groups at different speeds ( $p=$ 0.038). The High SCI group tended to have greater Ah2 than the Low SCI group in all chairs and at different speeds. In the SS condition, GPV (High SCI $=0.63 \pm 0.35 \mathrm{~g}$; Low SCI $=0.34 \pm 0.14 \mathrm{~g}$ ) was highest, followed by A4 (High $\mathrm{SCI}=0.42 \pm 0.19 \mathrm{~g} ;$ Low SCI $=0.29 \pm 0.09 \mathrm{~g}$ ), XTR (High $\mathrm{SCI}=0.51 \pm 0.29 \mathrm{I}$; Low SCI $=0.22 \pm 0.06 \mathrm{~g}$ ), and Boing!
$($ High SCI $=0.26 \pm 0.10 g$; Low SCI $=0.24 \pm 0.06 g$ ) (Figure 8(a)).

\section{Vertical Versus Horizontal Head Accelerations}

Comparison of peak vertical (Av1, Av2) and peak horizontal accelerations (Ah1, Ah2) showed that in all chairs regardless of speed, Av1 was greater than Av2; this indicates a decay in vertical acceleration in response to the applied vertical force. On the other hand, Ah1 was less than Ah2, indicating an increasing forward head acceleration in response to the applied vertical seat force. Moreover, Ah2 had the greatest acceleration magnitude in all conditions, particularly in those in the High SCI group versus the Low SCI group. This indicated that a delayed forward head motion occurred in response to the applied seat force and that the motion was greater in the High SCI than the Low SCI group.

\section{DISCUSSION}

All wheelchairs effectively reduced the forces and accelerations but varied in their shock- and vibrationsuppression performance. The difference in peak vertical 
(a)

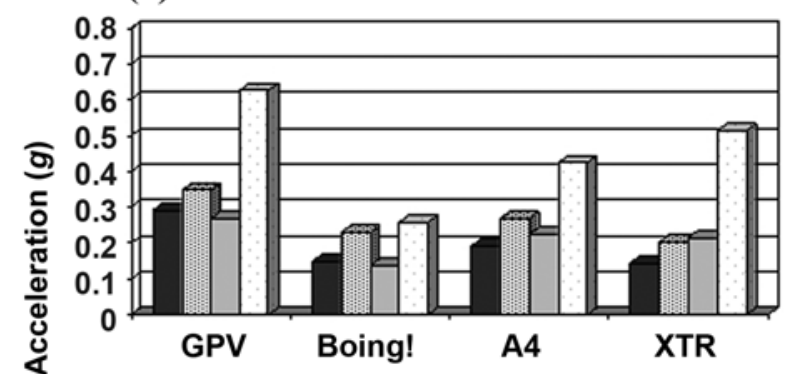

(c)

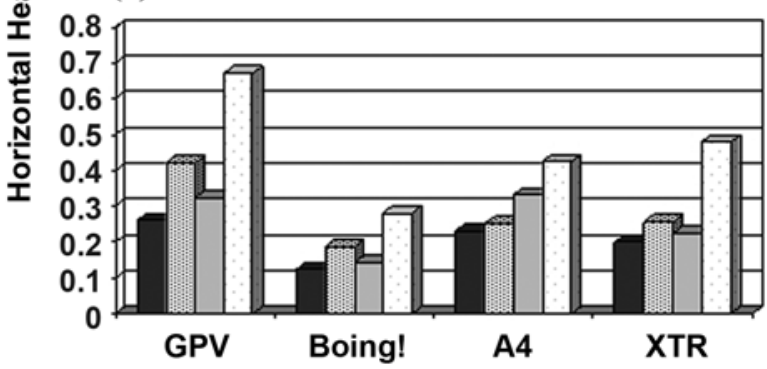

(b)

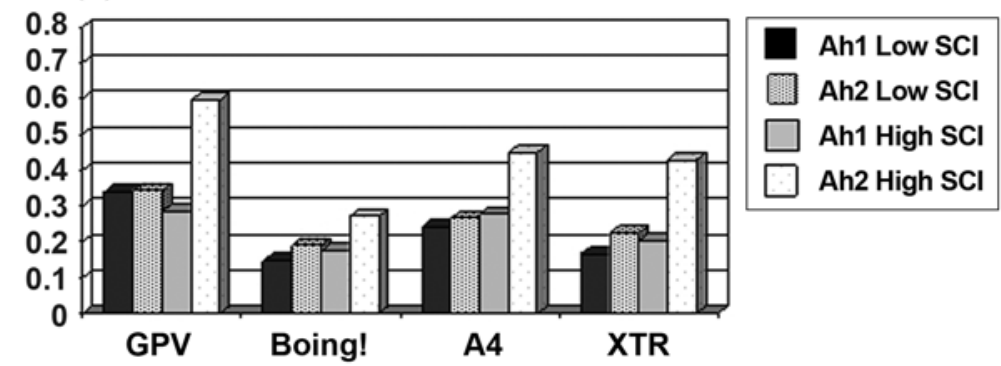

(d)

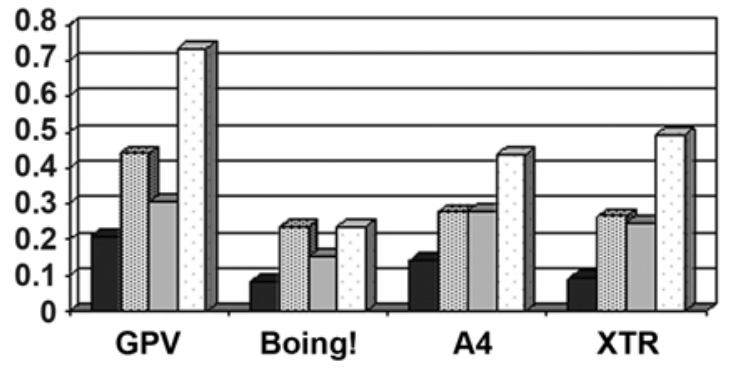

Wheelchair

Figure 8.

First (Ah1) and second peak horizontal head accelerations (Ah2) between subjects with high- and low-level spinal cord injury (SCI) in all wheelchairs during trials at (a) self-selected speed, (b) $0.85 \mathrm{~m} / \mathrm{s}$, (c) $1.03 \mathrm{~m} / \mathrm{s}$, and (d) $1.21 \mathrm{~m} / \mathrm{s}$.

accelerations indicated that all subjects experienced reduced head vertical acceleration in response to the initial impact (F1) and in response to the rear tires dropping onto the rotating drum (F2) for all chairs. However, while the difference in peak forces (F1 and F2) increased with increasing speed in the GPV, A4, and XTR, it remained relatively the same in Boing!. Moreover, Boing! had the lowest overall forces and head accelerations in all speed conditions, indicating less head motion was experienced by the riders with this chair-and potentially resulted in improved ride quality.

The peak seat forces are indicators of the shock- and vibration-absorption performance of the wheelchair (and rider) system. The difference in peak seat forces also indicated the amount of damping of the chair and rider system. If this change is small while the F1 is relatively large, then less damping of the chair occurs, resulting in a "springy" ride. On the other hand, if the F1 is relatively large and the change is large as well, then the damping is greater. Small F1s with sufficient damping would presumably translate to improved comfort, better ride quality, and reduced likelihood of secondary injury. The magnitudes of the peak head accelerations indicated the subsequent response of the rider to the applied seat forces. Relatively large initial peak accelerations would indicate greater head motion in response to the applied seat force. The difference in Ah1 and Ah2 would indicate the relative delay in reducing the head motion in response to the applied seat force. Small initial peak accelerations coupled with greater change (reduction) in head accelerations would presumably translate to less motion, improved head control and greater comfort—resulting in better ride quality. However, a controlled study using quantitative and subjective measurement tools would need to be performed to support this presumption.

Using the American National Standards Institute/ Rehabilitation Engineering and Assistive Technology Society of North America wheelchair testing standards and two test dummies to evaluate the seat and footrest vibrations on rigid and rear-suspension frames, Cooper et al. also determined that rear suspensions reduced some of the factors related to shock and vibration exposure by shifting the vibration transmitted to the wheelchair from a lower (7.81$9.84 \mathrm{~Hz}$ ) to a higher (12.40-15.63 Hz) octave [30]. Shifting vibrations away from the natural frequency range of humans (4-12 Hz) and reducing the amplitude or power 
may reduce the risk for injury [1]. However, since Cooper et al. categorized all tested rear-suspension types (elastomerbased, hydraulics, etc.) into a single group, they concluded that rear-suspension frames were not clearly superior to the traditional (rigid, folding) frame designs [30]. While the data analysis used by Cooper et al. differed from the analysis used here, both studies provide evidence for variability in the shock- and vibration-suppression performance between suspension frame types and provide an impetus for future research and development in the area of manual wheelchair suspension.

In the current study, we determined that different suspension configurations resulted in different force and acceleration reductions and that the spring-based independent suspension system used in the Boing! provided a smoother ride during the tested conditions than did the rigid (GPV) frame and the single hydraulic (XTR) and elastomer-based (A4) suspension designs. The greater SSs and reduced forces and accelerations observed in the Boing! suspension frame compared with other frames suggested a better overall vibration-suppression performance and potentially better overall ride, particularly for those with High SCI. While the Boing! may provide a better ride, the spring-based suspension system is heavier than its counterparts, which makes it difficult to transport and may contribute to the increased risk of upper-limb pathology secondary to increased weight when transferring in and out of a car, for example. Also, we anticipate that the vibration-suppression performance between chairs will vary with varying bump conditions, such as independent curb descents, during which shocks (large single-impact forces) are more prevalent than low-amplitude vibrations. Future developments using spring-based rear suspensions must minimize weight, including by using lightweight materials and novel structural configurations that require minimal frame assembly. Future research to identify optimal vibrationsuppression performance must closely examine the rider/ wheelchair response to different amplitudes and frequencies of forces.

For persons with High SCI to perform daily functions and be comfortable, they must constantly adjust and correct their posture to maintain their sitting balance, demonstrating the inseparable connection between dynamic sitting posture and function. Inference can also be made regarding additional work on the musculoskeletal system to maintain sitting posture as compared with those with intact trunk musculature. The lower SS chosen by those in the High SCI group suggests that they may tolerate less the increased loads associated with greater speed and prefer to minimize these loads, particularly when riding on a rigid-frame wheelchair. While those with High SCI experienced less seat forces and vertical accelerations than those with Low SCI, those with High SCI experienced greater horizontal head accelerations. The higher vertical seat force and head accelerations seen in the Low SCI group can be attributed to the higher SSs, but the higher head horizontal accelerations in the High SCI group can be explained by lack of trunk control. Those with High SCI will most likely stabilize the head via the neck. Consequently, those with High SCI may experience greater bending motions, particularly at the neck, in response to the applied perturbation. Increased bending motion is thought to increase the risk of spine and neck pain [8-9]. Boninger et al. investigated the prevalence of neck pain through physical examinations and questionnaires and determined that 66 percent of subjects reported neck pain since becoming a wheelchair user [10]. They identified vibration exposure and poor posture as risk factors for neck pain. Our results showing the greater horizontal head accelerations in those with High SCI provide evidence of the increased risk of neck pain, particularly in those with poor posture. The relationship among specific postural characteristics, vibration exposure, and development of neck pain is yet to be established.

The results from our evaluation may be limited to the range of conditions generated by the vibration simulator but provide a foundation for studies aimed at developing important analytical models of the biodynamics and control [31] of the wheelchair-rider system and greater understanding of the musculoskeletal loads the human rider experiences [32]. The vibration simulator created repeated low-amplitude bumps while the subject remained stationary, so whole-body forward momentum was absent. Furthermore, the bumps were applied only to the rear wheels and the effects of the front casters encountering the obstacle and front-wheel suspension were not assessed. Moreover, during actual wheelchair use, the rider plays an active part in modulating the forces applied to the body during each propulsion stroke [3] and can also react to the impending perturbation by preactivating innervated muscles [33]. Measurement of shocks and vibrations encountered in real-world situations (e.g., varied outdoor terrains) will include the contribution of the front caster [30] to the force and accelerations applied to the wheelchair frame [34] and the effect of the propulsion strokes of the human rider [3]. Our methods, while not truly 
replicating real-world situations, provided a controlled test condition for measuring the input-output relationship so crucial to the development of biodynamic models of the wheelchair-rider system and provided a means to evaluate the causal relationship between trunk control and vibration responses during wheelchair riding.

Application of vertical vibration to seated occupants is an approach widely used in research to understand human response to whole-body vibrations [35] and was used to develop the International Organization for Standardization (ISO) 2631 standard for acceptable exposure to wholebody vibration in industrial workers [1]. While the timedomain analysis techniques used in this study are unlike the frequency-domain analysis used by the ISO 2631, the approach and findings presented here provide the foundation for identification of important factors and parameters unique to those with SCI and those with less trunk control. Future studies will use both time- and frequency-domain analysis information in relation to measures of discomfort and fatigue. Use of an evidence-based approach to achieve a greater understanding of the specific factors contributing to discomfort, fatigue, onset of secondary injury, and prevention of such injuries will improve the design and prescription of suspension systems, which will enhance wheeled mobility and increase riders’ participation.

\section{CONCLUSIONS}

Wheelchair suspension reduced the force and accelerations experienced by manual wheelchair users and may improve the function of manual wheelchair users in terms of comfort at higher speeds, especially for users without trunk-muscle innervations. We determined that vibration exposure may depend on suspension configuration, trunkmuscle innervations, and speed and that minimizing the forces transmitted to the rider is important for ride quality. However, further research is needed for a full understanding of the relationships among shocks and vibrations, comfort level, and onset of injury.

\section{ACKNOWLEDGMENTS}

Special thanks to Somboon Maneekobkunwong, MS, for assistance with the instrumentations and data collections.
This material was based on work supported by the National Institute of Disability and Rehabilitation Research, grant H133E020732.

The authors have declared that no competing interests exist. Test wheelchairs were provided by Sunrise Medical, Colours ' $N$ Motion Inc, and Invacare Corp. The companies had no involvement in the study design; in the collection, analysis, and interpretation of data; in the writing of the report; or in the decision to submit the report for publication.

\section{REFERENCES}

1. International Organization for Standardization. Mechanical vibration and shock-Evaluation of human exposure to whole-body vibration-Part 1: General requirements. ISO 2631-1. Geneva (Switzerland): International Organization for Standardization; 1997.

2. Griffin MJ. Predicting the hazards of whole-body vibrationConsiderations of a standard. Ind Health. 1998;36(2):83-91. [PMID: 9583303]

3. VanSickle DP, Cooper RA, Boninger ML, DiGiovine CP. Analysis of vibrations induced during wheelchair propulsion. J Rehabil Res Dev. 2001;38(4):409-21. [PMID: 11563494]

4. DiGiovine CP, Cooper RA, Fitzgerald SG, Boninger ML, Wolf EJ, Guo S. Whole-body vibration during manual wheelchair propulsion with selected seat cushions and back supports. IEEE Trans Neural Syst Rehabil Eng. 2003;11(3): 311-22. [PMID: 14518796$]$

5. Cooper RA, Wolf E, Fitzgerald SG, Kelleher A, Ammer W, Boninger ML, Cooper R. Evaluation of selected sidewalk pavement surfaces for vibration experienced by users of manual and powered wheelchairs. J Spinal Cord Med. 2004; 27(5):468-75. [PMID: 15648802]

6. Wolf E, Pearlman J, Cooper RA, Fitzgerald SG, Kelleher A, Collins DM, Boninger ML, Cooper R. Vibration exposure of individuals using wheelchairs over sidewalk surfaces. Disabil Rehabil. 2005;27(23):1443-49. [PMID: 16418059]

7. Zimmermann CL, Cook TM, Goel VK. Effects of seated posture on erector spinae EMG activity during whole body vibration. Ergonomics. 1993;36(6):667-75. [PMID: 8513774]

8. Pope MH, Wilder DG, Magnusson ML. A review of studies on seated whole body vibration and low back pain. Proc Inst Mech Eng [H]. 1999;213(6):435-46. [PMID: 10635692]

9. Pope MH, Hansson TH. Vibration of the spine and low back pain. Clin Orthop Relat Res. 1992;(279):49-59.

[PMID: 1534724]

10. Boninger ML, Cooper RA, Fitzgerald SG, Lin J, Cooper R, Dicianno B, Liu B. Investigating neck pain in wheelchair 
users. Am J Phys Med Rehabil. 2003;82(3):197-202. [PMID: 12595772]

11. DiGiovine MM, Cooper RA, Boninger ML, Lawrence BM, VanSickle DP, Rentschler AJ. User assessment of manual wheelchair ride comfort and ergonomics. Arch Phys Med Rehabil. 2000;81(4):490-94. [PMID: 10768541$]$

12. Cooper RA, Boninger ML, Spaeth DM, Ding D, Guo S, Koontz AM, Fitzgerald SG, Cooper R, Kelleher A, Collins DM. Engineering better wheelchairs to enhance community participation. IEEE Trans Neural Syst Rehabil Eng. 2006;14(4):438-55. [PMID: 17190036]

13. Wolf E, Cooper RA, Pearlman J, Fitzgerald SG, Kelleher A. Longitudinal assessment of vibrations during manual and power wheelchair driving over select sidewalk surfaces. J Rehabil Res Dev. 2007;44(4):573-80. [PMID: 18247254]

14. Ebe K, Griffin MJ. Qualitative models of seat discomfort including static and dynamic factors. Ergonomics. 2000; 43(6):771-90. [PMID: 10902887]

15. VanSickle DP, Cooper RA, Boninger ML. Road loads acting on manual wheelchairs. IEEE Trans Rehabil Eng. 2000; 8(3):371-84. [PMID: 11001517]

16. Kerdanyan G, Minkel J, Maneekob Kunwong S, Waters R, Landsberger S. Measurement of force and acceleration experienced in a manual wheelchair. In: Proceedings of the 28th Annual RESNA Conference 2005; 2005 Jun 25-27; Atlanta, Georgia. Arlington (VA): RESNA; 2005.

17. Mansfield NJ, Griffin MJ. Non-linearities in apparent mass and transmissibility during exposure to whole-body vertical vibration. J Biomech. 2000;33(8):933-41. [PMID: 10828323]

18. Kitazaki S, Griffin MJ. Resonance behaviour of the seated human body and effects of posture. J Biomech. 1998;31(2): 143-49. [PMID: 9593207]

19. Hinz B, Menzel G, Blüthner R, Seidel H. Transfer functions as a basis for the verification of models-Variability and restraints. Clin Biomech (Bristol, Avon). 2001;16 Suppl 1: S93-S100. [PMID: 11275347]

20. Zimmermann CL, Cook TM. Effects of vibration frequency and postural changes on human responses to seated whole-body vibration exposure. Int Arch Occup Environ Health. 1997;69(3):165-79. [PMID: 9049667]

21. Matsumoto Y, Griffin MJ. Non-linear characteristics in the dynamic responses of seated subjects exposed to vertical whole-body vibration. J Biomech Eng. 2002;124(5):527-32. [PMID: 12405595]

22. Wolf EJ, Cooper MS, DiGiovine CP, Boninger ML, Guo S. Using the absorbed power method to evaluate effectiveness of vibration absorption of selected seat cushions during manual wheelchair propulsion. Med Eng Phys. 2004;26(9): 799-806. [PMID: 15564117]
23. Lundström R, Holmlund P, Lindberg L. Absorption of energy during vertical whole-body vibration exposure. J Biomech. 1998;31(4):317-26. [PMID: 9672085]

24. Holmlund P, Lundström R. Mechanical impedance of the sitting human body in single-axis compared to multi-axis whole-body vibration exposure. Clin Biomech (Bristol, Avon). 2001;16 Suppl 1:S101-10. [PMID: 11275348]

25. Holmlund P, Lundström R, Lindberg L. Mechanical impedance of the human body in vertical direction. Appl Ergon. 2000;31(4):415-22. [PMID: 10975668]

26. Palmer KT, Griffin MJ, Syddall HE, Pannett B, Cooper C, Coggon $\mathrm{D}$. The relative importance of whole body vibration and occupational lifting as risk factors for low-back pain. Occup Environ Med. 2003;60(10):715-21. [PMID: 14504358]

27. Samuelsson K, Larsson H, Thyberg M, Tropp H. Back pain and spinal deformity — Common among wheelchair users with spinal cord injury. Scand J Occup Ther. 1996;3(1):28-32.

28. Hobson DA, Tooms RE. Seated lumbar/pelvic alignment. A comparison between spinal cord-injured and noninjured groups. Spine. 1992;17(3):293-98. [PMID: 1566167]

29. Kemp B, Thompson L. Aging and spinal cord injury: Medical, functional, and psychosocial changes. SCI Nurs. 2002; 19(2):51-60. [PMID: 12510506]

30. Cooper RA, Wolf E, Fitzgerald SG, Boninger ML, Ulerich $\mathrm{R}$, Ammer WA. Seat and footrest shocks and vibrations in manual wheelchairs with and without suspension. Arch Phys Med Rehabil. 2003;84(1):96-102. [PMID: 12589628]

31. Seidel H, Griffin MJ. Modelling the response of the spinal system to whole-body vibration and repeated shock. Clin Biomech (Bristol, Avon). 2001;16 Suppl 1:S3-7. [PMID: 11275337]

32. Amirouche FM. Modeling of human reactions to wholebody vibration. J Biomech Eng. 1987;109(3):210-17. [PMID: 3657108]

33. Seidel H, Bluethner R, Hinz B. Effects of sinusoidal wholebody vibration on the lumbar spine: The stress-strain relationship. Int Arch Occup Environ Health. 1986;57(3):207-23. [PMID: 3957440]

34. Maneekobkunwong S. Effect of suspension on seat force experienced during wheelchair propulsion. In: Proceedings of the American Spinal Injury Association Annual Meeting; 2007; Tampa, Florida. Atlanta (GA): ASIA; 2007.

35. Mansfield NJ. Human response to vibration. Boca Raton (FL): CRC Press; 2005.

Submitted for publication January 10, 2008. Accepted in revised form May 5, 2008. 